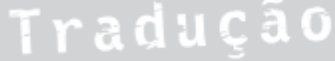

Carly Machado

(UFRRJ)

\title{
Religião e Mídia: reflexões de uma mente inquieta e o desafio de uma antropologia "sensacional"
}

A publicação desta primeira tradução de um texto de Birgit Meyer para o português marca um momento fundamental numa história de relações entre esta autora e o Brasil, e certamente vem preencher uma lacuna que não podia mais manter-se aberta. Meyer possui uma relação com o Brasil que já dura muitos anos. Realiza um amplo diálogo com pesquisadores da religião brasileiros (acolhendo-os frequentemente em seus grupos e projetos de pesquisa), já participou de eventos no país, orientou trabalhos que tratavam de grupos religiosos brasileiros, e mantém um intenso diálogo com a antropologia brasileira. Além de todos estes elementos, que não são poucos, destaco o fato de que pensar sobre a realidade brasileira e a religião no Brasil foi um dos elementos de especial importância à construção das questões intelectuais de Birgit Meyer. Não é à toa que, no texto que aqui se apresenta traduzido para o português, a autora introduz suas reflexões citando três exemplos etnográficos, sendo um deles um caso brasileiro. A publicação deste texto em português vem somar-se a esta antiga relação, intensificando-a e, espero, inspirando-a, tanto do lado de Birgit, quanto dos pesquisadores de língua portuguesa que poderão agora aproximar-se mais um pouco de suas ideias.

Birgit Meyer coloca-se desafios intelectuais bastante complexos. Podemos percebê-los rapidamente através dos próprios títulos de alguns de seus principais trabalhos. "Picturing the invisible", "Mediating absence", "How to capture de wow" são excelentes exemplos destes desafios a que me refiro, assim como "Mediation and Immediacy", título do artigo aqui traduzido.

Pesquisadora com enormes contribuições para os estudos antropológicos em variados campos, e especialmente para os estudos da religião, Birgit Meyer saboreia desafios teóricos como poucos. Uma das formas de introduzir a intenção do extenso trabalho de Birgit é apresentá-la como uma pesquisadora que assume como temática central de sua obra o dilema da definição das categorias pertinentes ao campo de estudos da religião, e o rendimento da contínua diluição 
O campo de pesquisas que mobiliza parte significativa dos estudos de Meyer é a relação entre "religião e mídia". Meyer problematiza de diferentes modos e em diferentes trabalhos a relação e as fronteiras entre religião e mídia. Se tomadas como entidades separadas, a autora afirma que a questão que se coloca é a de uma suposta "relação inesperada" entre estas duas categorias. No entanto, a provocação teórica e analítica colocada por Meyer não parte desta presumida separação, mas de uma relação intrínseca e de um processo de constituição recíproca entre mídia e religião.

Os problemas produzidos pela pesquisa neste campo de relações, articulações, sobreposições e, sobretudo, de desafios conceituais, alimenta a imaginação antropológica de Birgit desde seus estudos sobre o pentecostalismo em Gana, apresentado em seu livro Translating the Devil: Religion and Modernity Among the Ewe in Ghana, publicado em 1999. Já nesta obra Meyer procurava trabalhar de modo dinâmico com o problema da relação entre modernidade e religião, ao identificar em Gana um "novo encantamento do mundo" produzido pela relação com os elementos da modernidade e da tradição, ao invés do suposto e esperado desencantamento do mesmo. As pesquisas de Meyer contribuem assim de modo particular com os estudos africanistas tanto ao abordar o campo mais amplo da relação entre Religião e Modernidade, quanto ao tratar mais especificamente das apropriações do Cristianismo em Gana, das práticas pentecostais que ali se desenvolveram e expandiram, de sua relação com as religiões tradicionais locais, bem como ao dedicar-se a pensar a produção áudio visual daquele país nos últimos 20 anos, particularmente no que diz respeito ao lugar do cinema como mediação da relação das religiões e suas imaginações no espaço público em Gana.

Meyer afirma que seu interesse no estudo da mídia deveu-se à chegada da tecnologia de vídeo e seu desenvolvimento enquanto uma indústria do espetáculo em Gana. Esta realidade, afirma Meyer, a levou a corrigir sua visão limitada e parcamente discutida sobre a mídia, e assim desenvolver uma compreensão dinâmica da cultura como sendo simultaneamente afetada por e modeladora da "globalização" a partir da base (Meyer 2013:03).

O contato com o cinema em Gana foi o campo empírico produtor de grande parte das questões de pesquisa de Birgit, e as alimenta até hoje, mas certamente não foi o único. Umas das características do projeto acadêmico de Birgit Meyer é marcadamente o trabalho coletivo. De 2000 a 2006, Birgit mobilizou um amplo grupo de pesquisadores em torno do Pionner Project in Mass Media and the Imagination of Religous Communities, conduzido por ela na Universidade de Amsterdam, Holanda. As discussões no âmbito deste projeto, do qual tive o enorme prazer de participar ainda como estudante de doutorado, promoveu a reunião de e teve como resultado alguns dos grandes trabalhos de pesquisa sobre a temática Religião e Mídia desenvolvidos internacionalmente até hoje . Ao longo destes intensos anos, Birgit Meyer engendrou reflexões densas e complexas a partir do diálogo com campos de investigação realizadas por pesquisadores de África, Brasil, da Venezuela, de Bangladesh, do Caribe, bem como com estudos sobre pentecostalismo, catolicismo, islamismo, novos movimentos religiosos, dentre outros, sempre tomando por questão central a relação entre religião, mídia e espaço público.

Ao longo deste tempo, algumas temáticas concentraram mais intensamente sua atenção, sempre pensadas em articulação com o tema da religião: a questão da modernidade foi um de seus primeiros desafios intelectuais , e 
a mediação foi certamente um de seus temas mais recorrentes. Meyer define mediação como algo que se assenta em complexos processos de transmissão, e transmissões requerem intermediários (meios / mídias). As mídias, tal como entendidas por Meyer, não apenas transportam a mensagem de modo neutro, mas lhes dá forma em virtude de suas propriedades e propensões tecnológicas, sociais e estéticas, e através de formatos e formas específicas. $\mathrm{O}$ ato de mediação, assim compreendido, desperta sensibilidades através de apelos singulares aos órgãos dos sentidos e por carregar significados e valores específicos em sua própria forma (Meyer 2013).

A questão dos sentidos, a dimensão sensorial e sensacional (relativa às sensações), tornou-se gradativamente central à discussão feita por Meyer sobre seus principais temas. No que diz respeito ao tema da formação das comunidades, afirma Meyer, a dimensão corporal tem sido extremamente negligenciada. Não que esta não tenha importância empírica, mas não é devidamente abordada pela academia. No entanto, defende Meyer, o forte interesse no corpo, nos sentidos, na experiência e na estética nas ciências sociais e culturais assinala hoje uma crescente consciência de que o surgimento e a manutenção das formações sociais dependem de estilos que formam e vinculam os sujeitos não apenas através da imaginação cognitiva, mas também através da moldagem dos sentidos e dos corpos em construção (Meyer 2009). Esta é a base dos desafios do que denominei no título desta apresentação a antropologia "sensacional" de Birgit Meyer, e suas inquietações específicas.

O problema da imagem e da imaginação também concentrou boa parte dos esforços de pesquisa desta autora (Meyer 2015), assim como a questão da materialidade (Meyer 2016) e do patrimônio (Meyer e de Witte 2013). Ao tratar destas temáticas, Meyer atingiu diretamente categorias duras como a ideia de secularização quando, por exemplo, analisa não apenas a presença, mas a própria produção da magia na modernidade, ou a ideia mesmo de religião, quando esta é levada às últimas consequências ao ser pensada em relação e como mediação.

Mas é fundamental destacar que os debates teóricos enunciados por Birgit não possuem uma finalidade em si mesmos. Os conceitos pensados por esta autora ao articular religião, mídia e espaço público se produzem a partir de realidades sociais concretas, e retornam a elas apoiando reflexões sobre problemas públicos relevantes, tais como a emergência e a permanência de novas formas de comunidades, a formação de subjetividades, modos e meios de experiências religiosas, assim como formas de ser e agir no mundo. Meyer se interessa por discutir as diferentes formas através das quais as religiões afirmam sua presença na esfera pública, levando em consideração os paradoxos e tensões que daí derivam.

Ao invés de interpretar as apropriações às vezes espetaculares de novas mídias por grupos religiosos como um fenômeno inteiramente novo, a questão levantada por Meyer é a de como um novo meio interfere com meios de comunicação mais antigos que há muito fazem parte das práticas religiosas. Essa compreensão, afirma a autora, desloca a investigação do campo restrito e limitado das oposições binárias, nas quais a religião se apresenta como o Outro da modernidade e da tecnologia, cujo eventual desaparecimento é presumido (2006). A rearticulação da religião na contemporaneidade, discute a autora, implica necessariamente em uma espécie de transformação, que produz mudanças de posição em relação ao Estado e ao mercado, bem como na forma da mensagem religiosa, nas estruturas de autoridade e nos modos e nas disposições de vinculação e pertencimento a comunidades religiosas. 
Uma das razões pelas quais a religião continua a ser uma força vital e apelativa, afirma Meyer, reside exatamente em sua propensão para se transformar, incorporando novas mídias e abordando e ligando as pessoas de novas maneiras (Meyer 2009).

Os trabalhos mais recentes de Birgit Meyer fazem, por um lado, convergir este amplo conjunto de questões acumulado ao longo de sua intensa trajetória de pesquisa, mas, por outro lado, fomentam novas perguntas que estão em pleno despontar em sua obra. A tradução de seu artigo "Mediação e Imediatismo: formas sensoriais, ideologias semióticas e a questão do meio", publicado pela primeira vez em 2013, é sem dúvida uma enorme contribuição para os estudos antropológicos voltados aos temas da religião e da mídia no Brasil. Após mais de 15 anos de pesquisa acumulada no campo de religião e mídia ao redor do mundo, Birgit Meyer constata que "trabalhos recentes nesse campo criticam visões rasas da religião como algo que está em perigo de ser corrompido pelas forças de midiatização em massa, do entretenimento e da lógica de mercado, e afirmam que a adoção da mídia é chave para a manifestação da religião" (neste artigo).

Ao colocar como centro do problema neste artigo a questão do "imediatismo" na religião, a partir da relação religião e mídia, Birgit propõe "uma análise dos processos sociais pelos quais a mídia se tornou tão enredada naquilo que contribui para mediar que já não é mais visível enquanto tal, ao menos não para aqueles que estão participando da mediação". E pensando na mediação midiático-religiosa, conclui a autora: "Práticas de mediação religiosa parecem particularmente capazes de invocar o senso de presença imediata do divino" (neste artigo). Este é então o centro da questão da articulação entre mediação e imediatismo proposta por Birgit neste artigo, que mais uma vez sugere uma relação intrínseca entre categorias a princípio pensadas como opostas e excludentes.

Como já discutimos em outro momento (Machado 2014:141), aspectos relacionados à mídia religiosa e à presença da religião na mídia de massa frequentemente se fazem presentes nas pesquisas sobre o campo religioso brasileiro, mas poucas vezes são assumidos como questão central de análise. A leitura deste e outros trabalhos de Meyer pode certamente contribuir para a integração reflexiva destas questões na análise de vários campos de pesquisa sobre religião no Brasil, retirando as mídias das margens destes debate nos quais a relação entre religião e mídia aparece frequentemente sob a forma de mera descrição empírica e ainda, nos piores casos, quando são apresentadas com a finalidade exclusiva de denúncia de experiências consideradas superficiais ou mesmo deturpadas ou da vida religiosa.

Concluo esta apresentação destacando o que considero ser em última instância o cerne, ou prefiro pensar, o coração do trabalho de Birgit Meyer: a ética de sua inquietação intelectual. Birgit não se conforma, e esta inconformidade é seu compromisso político. Não se conforma às fronteiras disciplinares, e por isso produz pontes entre campos de estudos e campos disciplinares; não se conforma com a dureza das categorias, e por isso as dilui continuamente em seu laboratório de ideias, que está sempre fervilhando; não se conforma às dificuldades das pesquisas diante das novas tecnologias e do mundo social que se produz com elas, mas arrisca e fomenta novas metodologias e outros olhares para o campo; não se conforma com previsões e futurologias, mas sempre pergunta à realidade como as transformações se dão, e não onde elas vão dar; não se conforma com projeções feitas sobre 
a vida de outros, mas exige-se perguntar diretamente aos viventes sobre suas trajetórias, seus processos, suas invenções e imaginações; não se conforma com relações apresentadas como improváveis, inusitadas, e suspeitas, e ali onde havia suspeição por uma suposta contaminação nas fronteiras, Birgit instala uma profunda curiosidade por conexões e relações intrínsecas entre coisas que se apresentam juntas mesmo "quando não deveriam estar". Não se conforma com uma realidade social apresentada tal como esta "deveria ser", e suas supostas inconsistências e contradições, mas investe na construção de uma antropologia fundamentalmente curiosa e disposta que, diante de uma suposta contradição e de uma relação aparentemente inusitada, tem a coragem de repensar suas categorias ao invés de colocar sobre o outro um estatuto de contradição que tem como origem as categorias usadas para pensar sobre eles, e não sua experiência e vida social. Por estes e outros motivos, é com enorme prazer que apresento este artigo ao público de pesquisadores da religião de língua portuguesa, com o mais sincero desejo de que ele seja o primeiro de outras iniciativas de tradução da obra de Birgit Meyer, e apenas a porta de entrada de novos pesquisadores no mundo de suas inquietações antropológicas. 


\section{NOTAS}

1 "Sensacional" pode ser entendido como o atributo de algo relativo à sensação, aos sentidos, assim como de algo que causa uma sensação, ou uma grande emoção. "Sensational movies - Video, Vision and Christianity in Ghana" é o título de um dos livros de Birgit Meyer, publicado em 2015.

2 Birgit Meyer é você presidente do International African Institute.

3 Para uma visão geral das pesquisas desenvolvidas nesta época, ver MEYER, Birgit e MOORS, Annelise (org) Religion, Media and the Public Sphere (2006) e Meyer, Birgit (org) Aesthetic Formations: media, religion, and the senses (2009).

4 Meyer, Birgit \& Pels, Peter (eds.). (2003), Magic and modernity: interfaces of revelation and concealment. Stanford, Stanford University Press.

5 Meyer, Birgit (2014). Mediation and the Genesis of Presence (reprint of inaugural lecture), with a response on comments by Hans Belting, Pamela Klassen, Chris Pinney, Monique Scheer. Religion and Society: Advances in Research, 5, (pp. 205-254) (50 p.).

6 Uma das formas de Birgit apresentar o problema central do livro Magic and Modernity é dizer que pretendem discutir naquela obra as consequências de se pensar a magia "onde ela não deveria estar". 


\section{REFERÊNCIAS BIBLIOGRÁFICAS}

MEYER, Birgit \& de WITTE, M. 2013. Heritage and the Sacred, Special Issue of Material Religion: The Journal of Objects, Art and Belief. London: Bloomsbury Journals.

MEYER, Birgit \& MOORS, Annelies (eds.). 2006. Religion, media and the public sphere. Bloomington/Indianapolis, Indiana University Press.

MEYER, Birgit \& PELS, Peter (eds.). 2003. Magic and modernity: interfaces of revelation and concealment. Stanford, Stanford University Press.

MEYER, Birgit 2009. Aesthetic formations: media, religion, and the senses. Nova York, Pal-grave Macmillan.

MEYER, Birgit. 2013. "Material Mediations and Religious Practices of World-making". In K. Lundby (Eds.), Religion Across Media: From Early Antiquity to Late Modernity. New York: Peter Lang International Academic Publishers, pp. 1-19.

MEYER, Birgit. 2014. "Mediation and the Genesis of Presence (reprint of inaugural lecture), with a response on comments by Hans Belting, Pamela Klassen, Chris Pinney, Monique Scheer." Religion and Society: Advances in Research 5: 205-254

MEYER, Birgit. 2015. Sensational Movies - Video, Vision and Christianity in Ghana. Berkeley: University of California Press.

MEYER, Birgit (ed.). 2009. Aesthetic formations: media, religion, and the senses. Nova York, Pal-grave Macmillan.

MEYER, Birgit. 1998. "Make a complete break with the Past: memory and post-colonial modernity in Ghanaian discourse". Journal of Religion in Africa, 28(3):316-349. 